Session

\title{
The Reflection Technique: Increasing Classroom Involvement \& Learning
}

\author{
Mark L. Dean \\ Purdue University School of Technology
}

\begin{abstract}
Lecture-based teaching is the traditional didactic format. Some subject materials, for example mathematics, may lend themselves particularly well to such a format. However, other subject matter may be best mastered in an environment of interactive discovery, where issues can be discussed, debated, thought about, and struggled with in an open and relatively free flowing format. This paper presents such an interactive technique, termed the method of "reflection" by its founder, Dr. Stan Murrell, at the University of Louisville. The technique is particularly effective in smaller classes with fewer than 10-12 students. Simple to understand and utilize, the reflection technique provides a powerful tool for encouraging interaction and thoughtful discussion. In a nutshell, students are assigned responsibility for leading a class discussion based on an assigned reading. Rather than provide a summary of the material, the student is to provide his or her Reflections to that material. That is, what did they find interesting? What seemed to make sense? What didn't they agree with? What thoughts did the reading trigger? In general, what were their cognitive and affective reactions as they worked their way through the material? The student assigned responsibility for the Reflection leads the discussion by providing his or her reflections, but is also responsible for soliciting the input of others and their reflections. In addition to discussing the technique itself, this paper presents methods learned over time aimed at increasing the likelihood that students adequately prepare for class by thoughtfully reading the assigned material, grading reflections, and stimulating active and interactive discussion.
\end{abstract}

\section{Background}

Purdue New Albany's Organizational Leadership and Supervision (OLS) program is a relatively new, but growing, program. Consequently, some of our classes remain relatively small. We are also often required to teach at least three preps a semester, sometimes 6 different preps over the course of a year. Achieving expertise in one area is challenging. Achieving expertise in six is overwhelming. Such was the case my first semester. I was assigned to teach three classes. Two were on topics on which I had some expertise. The third, on the topic of change, had only 5 students in it, and I was no expert on the topic. Because of the size of the class, and because I lacked expertise in the topic, the idea of lecturing on the material did not appeal to me. In envisioning what the classroom experience might be like, perhaps even catastrophizing a little bit, I saw myself reading off of viewgraphs to a relatively disinterested - yea, even bored - group of students. It was not a pretty sight. 
Given these circumstances, I decided a different approach was needed. I needed something that would both stimulate student interest and interaction while not putting me in the role of "expert." Rather, what I chose to think of myself as was a facilitator. We needed a process wherein we could study and learn together. In considering possible methods for achieving this, I quickly recalled the reflection technique used by my mentor Dr. Stan Murrell at the University of Louisville. Dr. Murrell first introduced the technique in a psychotherapy class. It was nothing he researched or did studies on or wrote papers about. It was simply an approach he developed for use in certain of his graduate level classes. As a student, I found that the technique increased my motivation to read and prepare for class. It led to quite interesting and interactive class discussions, and these discussions significantly improved my comprehension and integration of the material. Given my positive experience as a student, I decided to try the reflection technique in my own classroom.

The reflection technique

The technique is beautiful in its simplicity. To explain, and also to model how one might incorporate this approach in their syllabus, let me provide an excerpt from one of my own syllabi:

\section{Reflections}

Responsibility for reflections will be assigned the first day of class. The person responsible for a reflection will lead a class discussion on the assigned material. Please note that this does not mean that you are to prepare a formal presentation, nor does it mean that you should summarize the reading. What I am looking for is an informal discussion of your reaction to various statements and points presented in the material. Did something strike you as particularly insightful? Useless? Interesting? Your classmates and I will also bring up our reflections as you move through the material. While grading will primarily be based on your class discussion, I would also like a one page summary of your reflection, which should simply provide a bulleted list indicating the points on which you are reflecting (but not your reflection!) and their page numbers. If for any reason you will not be present for one of your assigned reflections, you are responsible for trading with someone so that class is covered. ${ }^{1}$

As described, a student is assigned to lead the reflection for each reading. In providing his or her reflection, the student moves through the material, sharing any reactions to the text. The assumption is made that all students have read the material. Thus, the reflector is not to summarize nor teach what is in the text. Rather, he or she is to share with the class thoughts, comments, questions, associations, issues struggled with, in short - cognitive or affective reactions - that came to mind when he or she read the material. This typically leads to interactive and thought-provoking classroom discussion. In addition to providing his or her own reflection, the assigned reflector is also responsible for soliciting the reactions of others to the material.

That's the reflection technique it in a nutshell. Very simple to implement, yet very powerful in its ability to stimulate preparation, interaction, learning and integration of the material.

Proceedings of the 2004 American Society for Engineering Education Annual Conference \& Exposition

Copyright (c) 2004, American Society for Engineering Education 
In which classroom situations might it be an effective technique?

The reflection technique will likely be less effective in certain classroom environments, for example in large lecture halls, or when the information to be learned is very factual and/or precise, for example calculus, accounting, and most engineering classes. Similarly, when the professor uses material beyond that provided to the students in advance the technique will not be as effective.

However, it is expected that the reflection technique will be very effective with relatively smaller classes, when course content is based on qualitative and or philosophical material, rather than factual quantitative material. I have used it very successfully with a class size of 18 , and though I have no empirical data, I suspect that is approaching the limit of its effectiveness. The technique is probably most effective when a textbook (or other pre-assigned reading material) is the primary source of information. That is, when the professor is not adding a significant amount of material beyond the assigned readings. Also, the technique is effective when the information presented is qualitative rather than quantitative, when "right" and "wrong" answers are not easily discernible or are subject to differing opinions, and with philosophically or theoretically based materials.

\title{
An example
}

One of the courses in which I use the reflection technique is entitled "Leadership Philosophy." One of the texts used in the course is Margaret Wheatley's "Leadership and the New Science." Wheatley is a management theorist of sorts. Her book is very philosophical in nature, and she draws extensively on findings from the "New Science," that is, quantum mechanics, and creates metaphors for the leadership of organizations. The ideas presented are often radical compared to the students' past exposures to leadership and leadership theories and philosophies. Learning and integration often require significant student struggle and classroom discussion. The reflection technique provides a perfect avenue for such struggle and discussion.

My assumption is that the students have read the material. Moreover, the text provides the body of knowledge that we study. So in this class, I choose not to reiterate, in lecture format, what the book has already said. Rather, the reflection technique allows students to fully air, discuss, struggle with, and think about the ideas presented.

So, for example, in one part of her book Wheatley says "a living system produces itself; it will change in order to preserve that self." ${ }^{3}$ (p. 20). During class, one student might choose to respond to this particular idea with the comment "I don't really understand that. If it changes, is it the same system?" Another may muse "Well, think of a caterpillar and a butterfly - they are part of the same system." Another may related the idea back to an organization: "I wonder how we can apply this to organizations? The thought occurs to me that one way an organization stays the same yet changes is by responding to changing external conditions while maintaining a constancy of purpose in it vision." Thus, a classroom discussion emerges in which the students

\author{
Proceedings of the 2004 American Society for Engineering Education Annual \\ Conference \& Exposition \\ Copyright (c) 2004, American Society for Engineering Education
}


and professor engage in an exploration of the idea. Students remain engaged, and the learning process is stimulated.

Of course, the professor also has the opportunity to raise ideas and reflections. Thus, if the students do not initiate discussion of an idea the professor thinks particularly important, the professor can initiate the discussion.

Helping students prepare

Students are assigned responsibility for reflections on the first day of class. I typically ask students that have provided reflections before to volunteer to go first, as a model for students new to the technique.

The reflection technique is most effective as a learning tool when students have adequately prepared for class. If the material to be covered has not been read and studied, discussions may be flat, unenergetic, and uninformed. On the other hand, when students have prepared with proper study and thoughtfulness, classroom discussion and interaction can be very lively, invigorating, and filled with learning.

Based on feedback from students, I have developed two methods for encouraging student preparation in classes that employ the reflection technique. To help the student who is to lead the reflection, I require a single page, bulleted list of items to which the student is reflecting. Note that I do not want them to type up their actual reflection, that is, what they intend to say in class. But what I want them to do is simply identify the sentence or idea to which they are reflecting, and its page number. I do this for two reasons: first, to ensure they take the time to adequately prepare to lead the reflection. Second, I like having a piece of paper on which I can provide them feedback.

To encourage the students that will not be leading the reflection to prepare for class discussion, I typically have a quiz on the material at the beginning of a class. This was initiated due to experiences in which students did not prepare, and was suggested by students as a method to stimulate their preparation. I have found it to be effective. Quizzes are not intended to be technically difficult. That is, I do not expect that the students will have mastered the material. The quizzes are intended to stimulate sufficient reading and study so that the student might be an effective class participant. They are designed so that a person who has read the material, although not yet mastered it, might be successful.

\section{Grading}

Depending on the nature of the class, student reflections count from 10 to $30 \%$ of their grade, with the percentage allocated proportionally to the importance of class participation and interaction. Students will typically provide 4-6 reflections each over the course of a semester. In grading individual reflections, what I am looking for is evidence that the student thoughtfully read the material, effectively shared his or her thoughts with the class, and involved other students in the classroom discussion. I typically grade these assignments very easily. 
Student feedback on the technique

I have collected both qualitative and quantitative data from student regarding their reaction to the reflection technique. First, let me discuss qualitative data. On the last day of every class, in addition to filling out the forms required by the university, I facilitate what I call a "plus/delta" session to quickly elicit from students what they thought were the strengths of the course, and where they see opportunities for improvement. The reflection technique is invariably mentioned as a "plus," and students recommend that the practice should be continued.

With regard to quantitative data, I have administered a survey which included the following questions to members of classes in which I used the reflection technique:

1. Compared to traditional lecture classes, do you find the use of reflections more or less effective at increasing classroom interaction?

$\begin{array}{llll}\text { much less effective } & \text { less effective } \quad \text { mobout the same effective more effective }\end{array}$

2. Compared to traditional lecture classes, do you find the use of reflections more or less effective at increasing your classroom involvement?

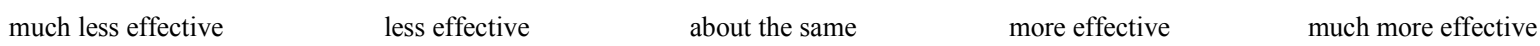

3. Compared to traditional lecture classes, do you find the use of reflections more or less effective at motivating you to prepare for class by reading the assigned materials?

way less effective $\quad$ less effective $\quad$ about the same more effective much more effective

4. Regarding the use of quizzes on assigned readings, how effective are the quizzes at getting you to read the assigned material?

not at all effective

not very effective

neutral

somewhat effective

very effective

5. Compared to traditional lecture classes, do you find the use of reflections more or less effective at increasing your interest during classtime?

$\begin{array}{llll}\text { much less effective } & \text { less effective } \quad \text { mobout the same effective more effective }\end{array}$

6. Compared to traditional lecture classes, do you find the use of reflections more or less effective at increasing your interest in the material outside of classtime?

much less effective

less effective

about the same

more effective

much more effective

7. Overall, compared to traditional lecture classes, do you find the use of reflections more or less effective at increasing your learning?

much less effective

less effective

about the same

more effective

much more effective 
8. Overall, would you prefer traditional lecture classes or classes using reflections?

Briefly summarizing the results of the survey, students overwhelmingly endorse that they find the use of reflections "more effective" or "much more effective" than a traditional lecture format for 1) increasing classroom interaction; 2) increasing their classroom involvement; 3) motivating them to prepare for class; 5) increasing classroom interest; 6) increasing their interest in the material outside of class time; and 7) increasing their learning. With regard to quizzes (item 4), students endorse that the use of quizzes is "somewhat effective" in getting them to read the assigned material. On item 8, students endorsed "Definitely reflection" when asked whether they would prefer traditional lecture classes or classes using the reflection technique.

\section{Conclusion}

The reflection technique, founded by Dr. Stan Murrell at the University of Louisville, is a method for engendering student preparation, stimulating classroom interaction, and enhancing student learning. It is simple to understand and utilize, but powerful in its results. It is likely most effective in relatively small classroom settings, when written course materials provide the foundation of the course, and when course concepts are qualitative or philosophical. Student preparation is critical to the success of the technique, and can be stimulated by the use of written reflection assignments and quizzes. In qualitative and quantitative studies, students overwhelming endorse greater preparation, interest, and learning in classes employing the reflection technique when compared to a traditional lecture format. Finally, in addition to learning course content, note that students achieve experiential development in formulating and developing their own ideas and providing them in a group setting. As ours is a leadership program, this is critically important to their development. Engineering educators may wish to consider use of the reflection technique in their own classrooms.

Bibliography

${ }^{1}$ Dean, M.L. (2004). Course syllabus: Leadership Philosophy. Spring 2004.

${ }^{2}$ Wheatley, M.J. (1999). Leadership and the New Science. Berret-Koehler. San Francisco.

${ }^{3}$ Wheatley, M.J. (1999). Leadership and the New Science. Berret-Koehler. San Francisco.

\section{Biographies}

MARK DEAN

Dr. Mark L. Dean is an assistant professor in the School of Technology at Purdue University, New Albany. Dr. Dean holds a Ph.D. from the University of Louisville in Clinical Psychology, a Master of Public Administration from IUPUI, and a Master of Electrical Engineering from the University of Louisville. He is an ASQ Fellow and Certified Quality Engineer. Prior to joining academia, Dr. Dean enjoyed a 23 year career in industry. 
Proceedings of the 2004 American Society for Engineering Education Annual Conference \& Exposition

Copyright (C) 2004, American Society for Engineering Education

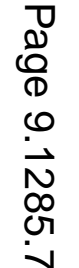

